\title{
EDUKASI PENDAFTARAN MEREK KEPADA PERANGKAT DESA DAN PELAKU UMKM MENUJU PEMULIHAN EKONOMI PASCA COVID-19 DI DESA SAWOJAJAR KABUPATEN LAMPUNG UTARA
}

\author{
Desy Churul Aini ${ }^{1}$, Rudi Natamihardja ${ }^{2}$, Bayu Sujadmiko ${ }^{3}$ \\ ${ }^{1,2,3}$ Universitas Lampung
}

Email : desy.churulaini@ fh.unila.ac.id ${ }^{1}$

\begin{abstract}
During the current pandemic, we seem to be forced to enter a new atmosphere in the digital sphere. Everything is done through social media and internet networks. The Covid-19 pandemic has changed patterns of behavior and human life in almost all countries, including Indonesia to be able to communicate virtually and almost all activities are supported by mobile phones. The Indonesian government is active in voicing economic activities that can support people's lives. In this case, MSMEs (Micro, Small and Medium Units) are an alternative for people who are going to open a business in a certain field whose main goal is to make a product that is worth selling and is in demand by the general public. MSME products from various products produced by business actors in Sawojajar village are directed to have their own characteristics and advantages by registering their product brands to attract consumers to compete with products packaged by a company. In order to achieve this, it is necessary to know how MSME actors can create a brand that is characteristic and becomes one of the rights legally obtained. So that the way the product is marketed through a market place or sold online will not cause legal polemics that will hinder the business process from developing towards global marketing. In the production process, the people of Sawojajar village still have problems related to trademark registration, permits, and marketing. This has given impetus to the Unila service team to hold brand registration education dissemination activities to village officials and MSME actors towards economic recovery after Covid-19 in Sawojajar village, North Lampung regency.
\end{abstract}

Keywords: Brand Registration, MSME Products, Covid-19

\begin{abstract}
Abstrak
Dimasa pandemi saat ini kita seakan dipaksa untuk memasuki suasana baru dalam lingkup digital. Semua dilakukan melalui sosial media, dan jejaring internet. Pandemi Covid-19 merubah pola perilaku dan kehidupan manusia hampir diseluruh negara, tak terkecuali Indonesia untuk dapat berkomunikasi secara virtual dan hampir seluruh kegiatan ditunjang dengan telepon genggam. Pemerintah Indonesia giat dalam menyuarakan aktifitas ekonomi yang dapat menunjang kehidupan masyarakat. Dalam hal ini UMKM (Unit Mikro Kecil Menengah) menjadi salah satu alternatif bagi masyarakat yang akan membuka suatu usaha dalam bidang tertentu yang tujuan utamanya adalah membuat suatu produk yang bernilai jual dan diminati oleh masyarakat umum. Produk UMKM dari berbagai produk yang dihasilkan oleh pelaku usaha di desa Sawojajar diarahkan dapat mempunyai ciri khas dan keunggulannya sendiri dengan mendaftarkan merek produknya untuk menarik minat konsumen agar dapat bersaing dengan produk-produk yang dikemas oleh suatu perusahaan.Demi tercapainya hal tersebut maka perlu diketahui bagaimana para pelaku UMKM dapat membuat suatu merek yang menjadi ciri khas tersebut dan menjadi salah satu hak secara legal yang didapatkan. Sehingga dengan cara produk tersebut dipasarkat melalui market place atau dijual secara online tidak akan menimbulkan polemik hukum yang akan menghambat proses usaha berkembang menuju pemasaran global. Dalam proses produksi, masyarakat desa Sawojajar masih memiliki permasalahan terkait pendaftaran merek, izin , dan pemasaran. Hal tersebut memberikan dorongan kepada tim pengabdi Unila untuk mengadakan kegiatan sosialisasi Edukasi pendaftaran merek kepada perangkat desa dan pelaku UMKM menuju pemulihan ekonomi pasca Covid-19 didesa Sawojajar Kabupaten Lampung Utara.
\end{abstract}

Kata Kunci: Pendaftaran Merek, Produk UMKM, Covid-19 
To cite this article:

Desy Churul Aini, Rudi Natamihardja, Bayu Sujadmiko. (2021). EDUKASI PENDAFTARAN MEREK KEPADA PERANGKAT DESA DAN PELAKU UMKM MENUJU PEMULIHAN EKONOMI PASCA COVID-19 DI DESA SAWOJAJAR KABUPATEN LAMPUNG

UTARA. Journal of Technology and Social for Community Service (JTSCS), Vol(1), 96-101.

\section{PENDAHULUAN}

Pada kegiatan sosialisasi kali ini, kita dapat melihat aspek yang dibutuhkan oleh masyarakat Sawojajar dalam proses menuju desa mandiri. Desa Sawojajar terletak di kecamatan Kotabumi Utara kabupaten Lampung Utara. Desa ini memiliki beberapa sektor UMKM home industri yang sedang digencarkan kepada masyarakatnya untuk menambah jumlah pemasukan bagi perekonomian masyarakatnya. Namun dalam hal ini masyarakat masih belum teredukasi mengenai pentingnya sebuah merek untuk produk yang akan mereka buat. Era globalisasi mendorong masyarakat agar dapat bersaing dalam membuat produk yang unggul dan terpercaya, oleh sebab itu UMKM adalah salah satu langkah masyarakat untuk semakin memajukan perekonomian desa Sawojajar secara khusus dan untuk Indonesia secara umum dengan segala produk yang akan diproduksi dan dijual ke masyarakat luas.

\section{Kekayaan Intelektual}

Hak Kekayaan Intelektual atau biasa disingkat "HKI" adalah padanan kata yang biasa digunakan untuk Intellectual Property Rights (IPR), yakni hak yang timbul bagi hasil olah pikir yang menghasilkan suatu produk atau proses yang berguna untuk manusia. Pada intinya HKI adalah hak untuk menikmati secara ekonomis hasil dari suatu kreativitas intelektual. Objek yang diatur dalam HKI adalah karya-karya yang timbul atau lahir karena kemampuan intelektual manusia. Menurut World Trade Organization (WTO), Hak kekayaan intelektual adalah hak yang diberikan kepada orang atas kreasi pikiran mereka. WTO biasanya memberi pencipta hak eksklusif atas penggunaan ciptaannya untuk jangka waktu tertentu. Hak Kekayaan Intelektual tidak berbeda dengan hak milik lainnya. Pemilik hak dimungkinkan untuk mendapatkan manfaat sepenuhnya dari produk yang pada awalnya merupakan gagasan yang dikembangkan dan dikristalisasi. Mereka juga akan mendapatkan hak untuk mencegah orang lain menggunakan, berurusan, atau merusak produknya tanpa izin sebelumnya. Pemilik dapat menuntut secara hukum dan memaksa untuk menghentikan dan memberikan kompensasi atas segala kerugian. Oleh karena itu, untuk menikmati objek yang dilindungi oleh HKI dibutuhkan suatu perjanjian yang disebut dengan perjanjian lisensi. Terdapat beberapa jenis perjanjian lisensi yaitu perjanjian lisensi yang memberikan seluruh hak eksklusif kepada penerima lisensi dan perjanjian lisensi yang memberikan hanya sebagian hak eksklusif seperti lisensi untuk produksi saja, atau lisensi untuk penjualan saja.

\section{Klasifikasi Kekayaan Intelektual}

Kekayaan intelektual mengacu pada ciptaan pikiran: penemuan; karya sastra dan artistik; dan simbol, nama dan gambar yang digunakan dalam perdagangan. WIPO membagi kekayaan intelektual menjadi dua kategori:

a. Properti Industri termasuk paten untuk penemuan, merek dagang, desain industri dan indikasi geografis.

Properti industri dapat dibagi menjadi dua area utama:

1. Satu area dapat dikarakteristikkan sebagai perlindungan tanda-tanda khusus, khususnya merek dagang (yang membedakan barang atau jasa dari satu pelaku usaha dengan usaha-usaha lainnya) dan indikasi geografis (mengidentifikasi barang yang berasal dari tempat di mana karakteristik disebabkan oleh asal geografisnya). Perlindungan terhadap tanda-tanda khusus tersebut bertujuan untuk merangsang dan memastikan persaingan yang adil dan melindungi konsumen, dengan memungkinkan mereka membuat pilihan berdasarkan informasi antara berbagai barang dan jasa. Perlindungan dapat bertahan tanpa batas waktu, asalkan tanda masuk tetap berbeda.

2. Jenis properti industri lainnya dilindungi terutama untuk merangsang inovasi, desain, dan penciptaan teknologi. Dalam kategori ini termasuk penemuan (dilindungi oleh paten), desain industri dan rahasia dagang. 
b. Hak cipta mencakup sastra karya-karya (seperti novel, puisi dan drama), film, musik, karya seni (misalnya gambar, lukisan, foto dan patung) dan desain arsitektur. Hak yang terkait dengan hak cipta termasuk kinerja artis dalam penampilannya, produsen rekaman suara dalam rekamannya, serta penyiar di radio dan program televisi.

Hak-hak penulis karya sastra dan artistik (seperti buku dan tulisan lain, komposisi musik, lukisan, patung, program komputer, dan film) dilindungi oleh hak cipta, untuk jangka waktu minimum 50 tahun setelah kematian penulis. Hak-hak yang juga dilindungi melalui hak cipta dan hak terkait adalah hak-hak para penampil (misalnya aktor, penyanyi, dan musisi), produser rekaman suara (rekaman suara), dan organisasi penyiaran. Tujuan sosial utama perlindungan hak cipta dan hak terkait adalah untuk mendorong dan menghargai karya kreatif.

\section{Sumber HukumHak Kekayaan Intelektual}

Secara global, terdapat dua konvensi yang menjadi dasar sumber hukum HKI di seluruh dunia, yaitu; Konvensi Paris untuk Perlindungan Properti Industri (1883) dan Konvensi Bern untuk Perlindungan Karya Sastra dan Artistik (1886). Konvensi Paris berlaku untuk properti industri dalam arti luas, termasuk paten, merek dagang, desain industri, model utilitas (semacam "paten skala kecil" yang disediakan oleh undang-undang beberapa negara), merek layanan, nama dagang (sebutan bagi kegiatan industri atau komersial yang dilakukan), indikasi geografis (indikasi sumber dan sebutan asal) dan penindasan persaingan tidak sehat.

\section{METODE PELAKSANAAN}

\section{Pelaksanaan}

Untuk meningkatkan kesadaran dan semangat UMKM desa Sawojajar terhadap pentingnya sebuah merek dalam produk mereka maka diselenggarakanlah Edukasi tentang pendaftaran merek kepada perangkat desa dan pelaku UMKM menuju pemulihan ekonomi pasca Covid-19 didesa Sawojajar Kabupaten Lampung Utara.

\section{Metode Pengabdian}

Metode yang dipergunakan dalam pelaksanaan sosialisasi Edukasi pendaftaran merek kepada perangkat desa dan pelaku UMKM menuju pemulihan ekonomi pasca Covid-19 didesa Sawojajar Kabupaten Lampung Utara adalah

1. Tim menyampaikan materi pengertian Pemahaman tentang Edukasi pendaftaran merek kepada perangkat desa dan pelaku UMKM menuju pemulihan ekonomi pasca Covid-19 didesa Sawojajar Kabupaten Lampung Utara.

2. Diskusi dan tanya jawab terkait Edukasi pendaftaran merek kepada perangkat desa dan pelaku UMKM menuju pemulihan ekonomi pasca Covid-19 didesa Sawojajar Kabupaten Lampung Utara.

\section{HASIL DAN PEMBAHASAN \\ Perencsanaan}

Kegiatan Edukasi Pendaftaran Merek kepada Perangkat Desa dan Pelaku UMKM menuju pemulihan ekonomi Pasca Covid-19 di Desa Sawojajar Kabupaten Lampung Utara sesuai yang direncanakan dalam program jurusan bagian Hukum Internasional Fakultas Hukum Unila, dapat berjalan dengan baik.

Sebelum dilakukan kegiatan sosialisasi Tim Pengabdian Jurusan Hukum Internasional Fakultas Hukum UNILA, terlebih dahulu melakukan survei lokasi dan menghubungi pihak aparat desa Sawojajar Lampung Utara, yang dalam hal ini tim dari FH berhubungan dengan Bapak Kepala Desa Mulyanto yang membantu secara teknis proses pelaksanaan kegiatan penyuluhan ini. Hasil dari survei lapangan tersebut tim kami sudah mendapat gambaran kondisi kemampuan serta pengetahuan dasar kelompok sasaran dalam hal ini adalah perangkat desa dan pelaku UMKM dalam pemahaman dan pengetahuan tentang bagaimana mendaftarkan merek yang merupakan salah satu hak milik dalam bidang kekayaan intelektual dimana hal ini merupakan salah satu upaya dalam mengangkat industri keripik yang ada di desa tersebut sebagai produk unggulan agar dapat bersaing secara global dengan pemberian merek, karena merek produk selain sebagai identitas juga merupakan jaminan kualitas produk. Jaminan kualitas produk sangat diperlukan oleh produsen dalam meningkatkan produktivitas dan pendapatan. Hal ini akan menunjang perekonomian dan daya beli masyarakat secara khusus di desa Sawojajar - Lampung Utara. Kemudian diadakan negosiasi dan kesepakatan bersama untuk dilakukan edukasi pendaftaran merek melalui kegiatan 
penyuluhan bagi perangkat desa dan pelaku UMKM, termasuk waktu, tempat, panitia yang terlibat dan pendanaan dari pelaksanaan kegiatan tersebut.

Pada saat akan dilakukan penyuluhan, terlebih dahulu dilakukan wawancara dan perbincangan kepada para aparat desa dan pelaku UMKM untuk lebih meyakinkan Tim Pengabdian Unila terhadap gambaran, kemampuan serta pengetahuan dasar kelompok sasaran dalam pemahaman tentang wawasan Edukasi Pendaftaran Merek kepada Perangkat Desa dan Pelaku UMKM menuju pemulihan ekonomi Pasca Covid-19 di Desa Sawojajar Kabupaten Lampung Utara dan bagaimanakah pengenalan perangkat desa dan pelaku UMKM tentang bahasan tersebut. Berdasarkan hasil wawancara dan perbincangan sebagian besar kelompok sasaran tidak dapat menjawab pertanyaan Tim Pengabdian dan menyatakan bahwa sebelumnya mereka belum mendapatkan materi itu.

Berdasarkan gambaran diatas, secara menyeluruh dapat dikatakan bahwa kemampuan dasar calon peserta penyuluhan ini tentang pendaftaran merek sebuah produk masih rendah. Kondisi ini dapat dimaklumi karena para peserta belum pernah mendapatkan pengetahuan dan pemahaman serta penyuluhan tentang pendaftaran merek sebuah produk perangkat desa dan pelaku UMKM.

\section{Pelaksanaan}

Salah satu proses yang dapat dilakukan untuk meningkatkan pengetahuan masyarakat adalah melalui penyuluhan. Metode penyuluhan dilakukan untuk mentransfer pengetahuan dan informasi yang tepat kepada masyarakat sehingga diharapkan dapat terjadi peningkatan pengetahuan tentang pendaftaran merek sebuah produk bagi perangkat desa dan pelaku UMKM.

Berkenaan dengan hal tersebut, maka melalui kegiatan ini dilakukan penyuluhan tentang hal-hal yang berhubungan dengan pendaftaran merek sebuah produk bagi perangkat desa dan pelaku UMKM, yang bertempat di Balai Desa, Desa Sawojajar Kabupaten Lampung Utara yang dilaksanakan pada tanggal 4 Agustus 2021, yang diikuti oleh 56 (lima puluh enam) peserta yang terdiri dari ibu-ibu penggerak PKK, perangkat desa dan pelaku UMKM di desa Sawo Jajar Lampung Utara. Kegiatan penyuluhan ini pada saat pelaksanaan meminta kepada para peserta untuk mengisi daftar hadir peserta disertai dengan saran dan manfaat yang mereka dapatkan dari kegiatan ini. Diharapkan dengan penyuluhan tersebut, mereka mendapatkan pengetahuan dan informasi yang menjadi bekal bagi mereka untuk mengenal tentang cara melakukan pendaftaran merek sebuah produk.
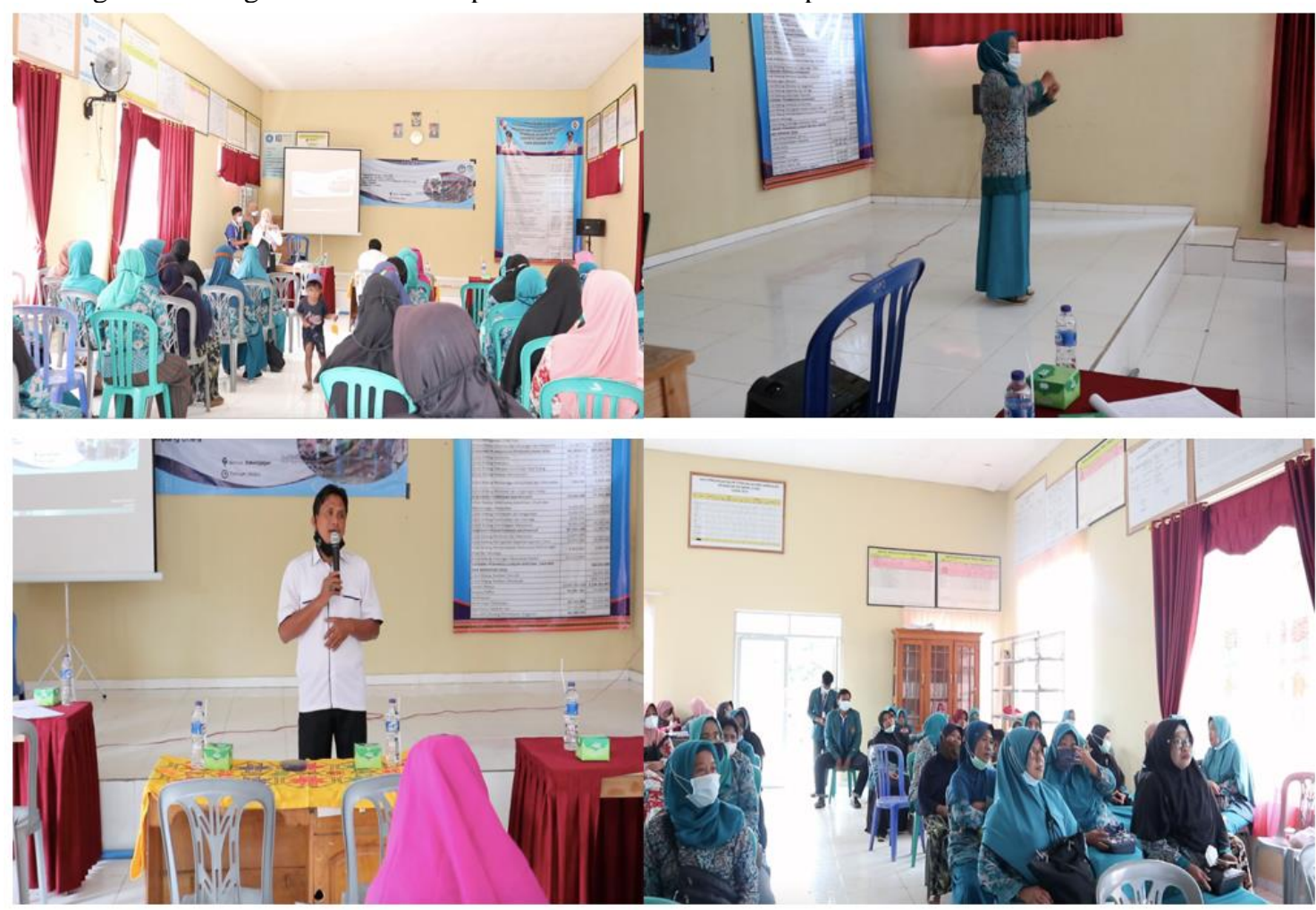

Gambar 1. Pemberian Materi 
Narasumber penyuluhan merupakan praktisi akademisi yang berasal dari Bagian Hukum Internasional Fakultas Hukum UNILA yang menguasai persoalan di bidangnya. Adapun materi yang disampaikan oleh narasumber adalah sebagai berikut:

Tabel 1. Pemberian Materi

\begin{tabular}{|l|l|l|l|}
\hline NO & \multicolumn{1}{|l|}{ M A T E R I } & NARA SUMBER & KEPAKARAN \\
\hline 1. & Pengantar Haki & Rudi Natamiharja & Ilmu Hukum \\
\hline 2. & $\begin{array}{l}\text { Pengaturan UU Nomor 20 Tahun 2016 } \\
\text { tentang Merek dan Indikasi Geografis }\end{array}$ & Bayu Sujadmiko & Ilmu Hukum \\
\hline 3. & Prosedur Pendaftran Merek di DJKI & Desy Churul Aini & Ilmu Hukum \\
\hline
\end{tabular}

Kegiatan penyuluhan berjalan dengan baik dan lancar, terlihat dari antusias para peserta ibu-ibu PKK, pelaku UMKM dan aparat desa dalam diskusi dan Tanya jawab. Beberapa permasalahan yang menyangkut cara melakukan pendaftaran merek sebuah produk ini pun dibahas, mereka memberikan pertanyaan-pertanyaan yang kritis tentang materi ini. Kendala utama yang dihadapi adalah sinyal internet yang kurang memadai sehingga pemateri hanya dapat melakukan simulasi cara melakukan pendaftaran merek sebuah produk melalui video singkat tanpa bisa dipraktekkan langsung oleh peserta. Para peserta yang semuanya ibu-ibu ini juga cenderung belum terbiasa dengan penggunan media teknologi informasi dan komunikasi seperti gawai (baca: hp) dan laptop. Materi pelatihan secara lengkap terdapat pada lampiran.

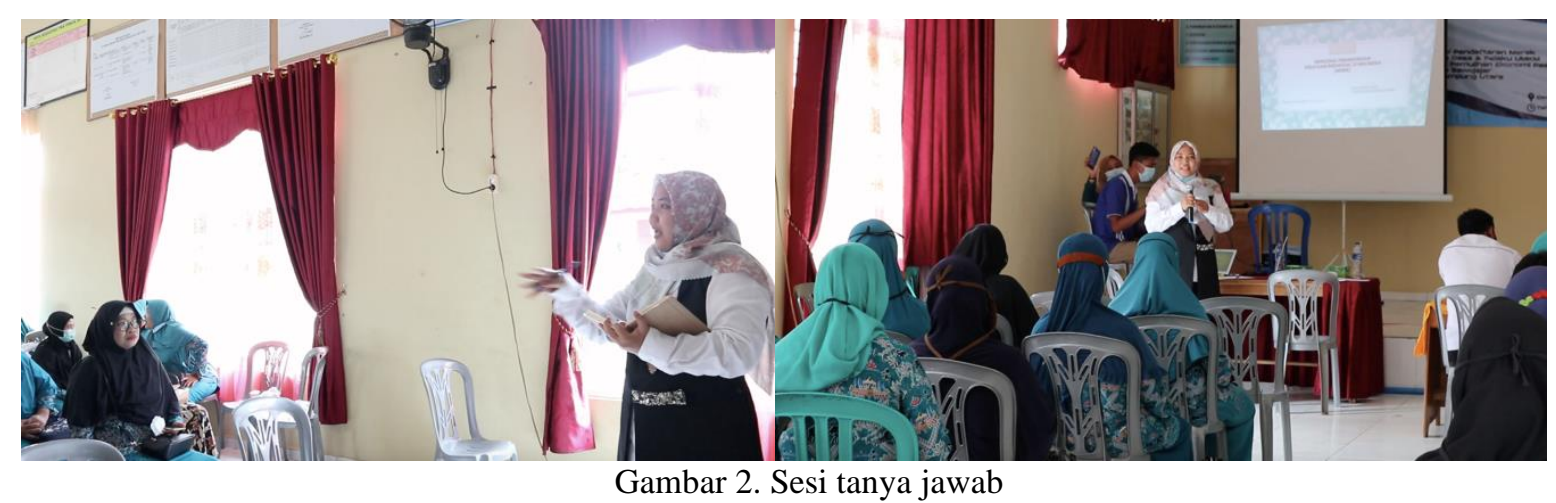

\section{Faktor Pendukung}

Faktor pendukung kegiatan penyuluhan ini dapat dilaksanakan dengan baik karena didukung oleh faktorfaktor sebagai berikut:

a. Apresiasi, kemauan, minat dan perhatian yang cukup besar dari peserta dan Tim baik sebelum, maupun sesudah penyuluhan.

b. Rasa ingin tahu peserta sangat besar mengenai cara melakukan pendaftaran merek sebuah produk.

c. Kesungguhan dan motivasi para peserta baik ibu-ibu PKK, pelaku UMKM dan aparat desa.

d. Peserta bersedia meluangkan waktu sepenuhnya, karena keingintahuan mereka tinggi.

e. Dukungan dari Tim Pengabdian dari Fakultas Hukum UNILA, yang memiliki pengetahuan, kemampuan dalam penyuluhan hukum tentang masalah hukum hak kekayaan intelektual.

f. Bantuan tehnis dan kepercayaan dari pihak apparat desa terutama Kepala Desa Sawojajar Kabupaten Lampung Utara untuk melaksanakan penyuluhan dan pembinaan.

\section{Faktor Penghambat}

Terdapat beberapa hambatan yang dihadapi dalam kegiatan penyuluhan diantaranya sebagai berikut: 
a. Terbatasnya ruang, waktu dan dana yang tersedia, sehingga bimbingan dan penyuluhan yang diberikan kurang maksimal.

b. Terkendala masalah-masalah tehnis antara lain sinyal internet yang kurang memadai sehingga pemateri hanya dapat melakukan simulasi cara melakukan pendaftaran merek sebuah produk melalui video singkat tanpa bisa dipraktekkan langsung oleh peserta.

c. Para peserta yang semuanya ibu-ibu ini juga cenderung belum terbiasa dengan penggunan media teknologi informasi dan komunikasi seperti gawai (baca: hp) dan laptop.

\begin{abstract}
KESIMPULAN
Pelaksanaan Edukasi Pendaftaran Merek kepada Perangkat Desa dan Pelaku UMKM menuju pemulihan ekonomi Pasca Covid-19 di Desa Sawojajar Kabupaten Lampung Utara, yang diselenggarakan pada hari Rabu, tanggal 4 Agustus 2021 dapat disimpulkan yaitu Tingkat pengetahuan dan pemahaman para peserta baik ibu-ibu PKK, pelaku UMKM dan aparat desa tentang cara melakukan pendaftaran merek sebuah produk sebelum dilakukan sosialisasi masih rendah. Hal ini tercermin dari pertanyaan-pertanyaan yang diajukan kepada narasumber dari peserta penyuluhan sebelum materi penyuluhan diberikan, dimana terlihat peserta belum memahami arti penting dari pendaftaran merek dan bagaimana cara melakukan pendaftaran terhadap produk tersebut. Pengetahuan dan pemahaman peserta kegiatan edukasi pendaftaran merek kepada perangkat desa dan pelaku UMKM menuju pemulihan ekonomi Pasca Covid-19 di Desa Sawojajar Kabupaten Lampung Utara sesudah penyuluhan meningkat. Indikator kesimpulan ini didapat dari terjawabnya dengan baik pertanyaan-pertanyaan yang diajukan oleh narasumber kepada para peserta tentang arti penting dari pendaftaran merek dan bagaimana cara melakukan pendaftaran terhadap produk tersebut.
\end{abstract}

\title{
UCAPAN TERIMAKASIH
}

Ucapan terima kasih terutama kepada Universitas Lampung dalam hal ini adalah Lembaga Penelitian dan Pengabdian kepada Masyarakat yang telah memberikan kegitan pengabdian pemula tahun 2021 kepada tim pengabdi; Kedua, ucapan terima kasih kami sampaikan kepada segenap pihak yang membantu dalam mensukseskan kegiatan ini yaitu seluruh aparat Desa Sawojajar Kabupaten Lampung Utara termasuk jajaran pengurus ibu-ibu PKK Desa Sawojajar serta mahasiswa bagian hukum internasional yang turut berpartisipasi menjadi panitia tehnis dalam kegiatan ini.

\section{REFERENSI/DAFTAR PUSTAKA}

Adrian Sutedi, Hak Atas Kekayaan Intelektual Jakarta : Sinar Grafika, 2010.

Dani Amran Hakim, Pengecualian Perjanjian Hak Kekayaan Intelektual Dalam Hukum Persaingan Usaha, Fiat Justisia, Vol. 9/No.4/2015.

Ermansyah Djaja, Hukum Hak Kekayaan Intelektual Jakarta : Sinar Grafika, 2009.

Fahmi, M. Abdi Almaktsur, dan Syafrinaldi, Hak Kekayaan Intelektual. Pekanbaru:, Suska Press 2008.

Iswi Hariyani, Prosedur Mengurus Haki Yang Benar. Jakarta: Pustaka Yustisia, 2010.

Purwosujipto, Pengertian Pokok Hukum Dagang I Pengetahuan Dasar Hukum Dagang. Jakarta: Djambatan, 1991.

Rahmi Janed, Hukum Merek Trade Mark. Jakarta : Kencana, 2015.

UU No. 20 Tahun 2016 tentang Merek dan Indikasi Geografis

https://accurate.id/marketing-manajemen/apa-itu-branding-dan-mengapa-itu-penting/

https://www.easybiz.id/ini-alasan-pendaftaran-merek-penting-bagi-umkm-untuk-mengembangkan-bisnis/

https://www.easybiz.id/ini-alasan-pendaftaran-merek-penting-bagi-umkm-untuk-mengembangkan-bisnis/

Direktorat Penelitian UGM, Pengertian HKI, https://penelitian.ugm.ac.id/pengertian-hki/

WTO, TRIPS: What Are IPRS, https://www.wto.org/english/tratop_e/trips_e/intel1_e.htm

Dubai Customs, What is IPR, https://www.dubaicustoms.gov.ae/en/IPR/Pages/WhatIsIPR.aspx

WIPO, Summary of the Paris Convention for the Protection of Industrial Property (1883), https://www.wipo.int/treaties/en/ip/paris/summary_paris.html

WIPO, Summary of the Berne Convention for the Protection of Literary and Artistic Works (1886), https://www.wipo.int/treaties/en/ip/berne/summary_berne.html 